\title{
INTRODUCTION: A LingUiSTIC 'RE-TURN’ IN TRANSLATION STUDIES?
}

\author{
Willy Vandeweghe - Sonia Vandepitte - Marc Van de Velde \\ Hogeschool Gent
}

In its early, pre-theoretic stage, Western Translation Studies took most of its inspiration from Bible translation study and the study of literature and philosophy. Heated debates concerned the balance between source and target text orientation, matters of loyalty and treason, freedom and literalness. The writings on translation were speculative, or prescriptive, or both. Only the second half of the twentieth century witnessed the advent of Translation Studies (TS) as a descriptive discipline.

However, the complexity and multi-facetedness of translation as a research object does not allow descriptive Translation Studies to rely on just one research design or paradigm of general application. The hybrid and in some sense still emerging (inter)discipline of Translation Studies is characterized by trends and changes, giving rise to the 'turn' metaphor which is so popular in precisely this research area (cf. SnellHornby 2006), as it fits in so well with the concept of a discovery journey with travellers following different and unpredictable paths.

When Translation Studies finally set out its project as a descriptive science - the term 'Translation Studies' was coined by Holmes in the seventies - many authors defined it as a branch of linguistics. As in the earlier days, it was still the relation between the source text and the target text which was at the forefront, and notions like 'procedure' (Vinay-Darbelenet 1958) and 'shift' (Catford 1965) became pack and parcel of the discourse on translation, both of them intimately tied up with the muchdebated notion of 'equivalence'. The early linguistic approaches had a tendency to view the translation operation as primarily a transcoding operation, a narrowing down of the scope which explains much of the criticism levelled against this approach in subsequent years. These years, then, saw a widening of the research scope to functional, cultural, sociological, political and ideological matters, a process reflecting an inside-out movement from the centre to the periphery, much like the recording of an onion peeling being projected backwards. The functional and the cultural moves constituted acts of contextualizing, not only of the translation phenomena in themselves, but also of the whole translation enterprise. The perspective was rightly broadened up by those writers who were pointing at ideology and oppression, and bringing to the fore the translators themselves with the social, professional, ethical, ideological conditions within which they perform their mediating role. Every new layer to be explored in the translation 
situation, may inspire to new kinds of 'turns', be they 'political', 'social', 'ideological' or whatever (recent titles are Wolf ed. 2006, Wing-Kwong Leung 2006).

Early hopes after World War II that formalization and automation of the translation process would enable the consignment of tedious and repetitive tasks to machines led to the prospect that linguistics, especially the variant modelling language in algorithms, would solve even the problem of machine translation. When the 1966 ALPAC report smashed this hope to smithereens, funding of machine translation development was cut down, and an end was put to the naive ideas some might have had that transcoding was all there was to the translation enterprise. The debate on the notion of equivalence as a relevant or useful cornerstone of translation theory seemed to have been concluded by the proponents of Snell-Hornby's integrated approach of translation (Snell-Hornby 1988) by the end of the eighties. At the same time, however, a growing translation industry making use of the channels of globalization could not move on without just taking some concept of equivalence for granted.

The same technological innovations which fuelled the rise of the translation industry also led to the composition and use of huge language and translation corpora. Witness to the growing awareness of the opportunities offered by large corpora, monolingual and multilingual, are Baker's programmatic articles on corpus Translation Studies (1993, 1995), in which she propagates the building of different sorts of corpora. Among them are parallel corpora providing aligned versions of translated and original material, offering empirical material for wide-scope studies on the translation process. TS will? also benefit from multilingual corpora collecting texts that are comparable in theme and design, but do not entertain a translation relation, and from monolingual comparable corpora, which Baker sees as "a cross between parallel and multilingual corpora" (1995: 234). The latter allow the researcher to establish the linguistic and textual particulars of translated vs. non-translated material.

Corpus studies prominently brought linguistics back onto the scene, and came to be integrated into the models set up by authors usually associated with the study of literary translation, like Toury's Descriptive Translation Studies (1995). This renewed linguistic interest fuelled by the new methodological tools resulted in a new research paradigm, allowing for innovative research questions to be explored. One of these is the quest for translation universals, both target-oriented 'T-universals' dealing with the translation product, and source-oriented 'S-universals' having to do with the translation process (for the distinction, see Chesterman 2004). The former rank among the phenomena with a higher distribution in translated texts than non-translated texts, irrespective of the source language or translation direction. S-universals, then, are hypotheses claiming "to capture universal differences between translations and their source texts, i.e. characteristics of the way in which translators process the source text" (Chesterman 2004: 39). The product-oriented hypotheses can profitably be investigated by consulting comparable corpora, whereas the process-oriented ones may emerge among other things - from the study of parallel corpora.

After the early and somewhat mistaken attempts of linguistics to export its systembased models to the study of translation, it has itself evolved in the direction of usagebased models. Both linguistics and TS developed along similar paths:

Das Entstehen der Textlinguistik, die zunehmende Berücksichtigung der kommunikativen Einbettung der Sprache und des Textes, die pragmatische und die kognitive 
Wende in der Linguistik sind Entwicklungen, die sich in der Geschichte translationswissenschaftlicher Theorien und Modellen widerspiegeln. (Van Vaerenbergh 2004: 18)

The rise of text linguistics, the increasing consideration of the communicative embedding of language and text, the pragmatic and cognitive turns of linguistics are developments which are reflected in the history of translation theories and models. (our own translation, eds.)

Despite the close relationship between linguistics and TS, the interest is not necessarily mutual. "Whereas translation scholars have generally been prepared to accept linguistic theorizing of linguistic data, linguists have been far less interested in discovering how translation scholars theorize data that they consider theirs." (Malmkjaer 2005: 17-8).

Translation Studies in the second half of last century witnessed the hermeneutic move (the 'move' metaphor preceded the 'turn' metaphor), the cultural turn in the eighties, the postcolonial turn in the nineties. After all this moving and turning, it might seem as if Translation Studies is now in some way 're-turning' to linguistics, but the image is out of place since the linguistic approach has never been that far away from the evolution of TS, "simply because some level of linguistic analysis must, at the very least, form the starting point of any study of translation" (Baker 2004: 291) and because linguistics plays an important role in translation training, translation criticism and translating (Malmkjær 2006). Moreover, the linguistic and the cultural approach are inseparable and mutually reinforcing, in much the same way as the translator's competence is not 'linguistic' or 'cultural', but 'linguacultural' (House 1997). All this implies that TS as an interdiscipline extends beyond linguistics: many scholars look outside the text in their search for explanations of features of the textual profile, or for fuller descriptions of the consequences of linguistic choices. Translation Studies needs both the microscope and the telescope, as Maria Tymoczko (2002) has argued.

\section{Slt06}

What led the organizers to take the initiative of the 2006 congress on "The Study of Language and Translation' was the conviction that interpretation and linguistic transfer are at the heart of the translational enterprise, its alpha and omega. However much this idea of 're-turn' fits in with the fashionable 'turns' metaphor, there was a general feeling at the congress that linguistics had never been far away from the centre of the TS discipline.

To clearly mark the point of linguistics being prominent in the scientific study of translation from its early beginnings, the organizers did not only select scholars that have focussed on linguistic aspects in Translation Studies as their keynote speakers Kirsten Malmkjær, Andrew Chesterman, Christiane Nord and Mona Baker - but they also had the honour to welcome as a special guest speaker ninety-two-year-old Eugene Nida, who already in the first half of the twentieth century enthusiastically introduced linguistic ideas into the study of (Bible) translation, as is witnessed in his 1945 study on the relevance of linguistics and ethnology in the discussion of translation problems (Nida 1945). 


\section{This volume}

Many of the contributions to this volume are in some way or another tributary to the corpus approach with its focus on corpus methodology and universals research. In fact, various methodologies are suggested for the investigation of similarities, metacommunication, borrowings, collocations, and so on. References are made to both S-universals and T-universals. The relationship between types of findings, hypotheses and domains of study is explored and results are given of investigations into prosodic, linguistic and textual features of various types of translation corpora.

Some studies are more general in focus, like the ones by Chesterman and Halverson, and in a sense Nord's contribution on metacommunication as well. Pointing out that Translation Studies most often gives pride of place to differences rather than similarities, Chesterman argues in favour of what he calls translation profiles in which similarities, too, play a considerable role. To him, such a translation profile basically consists of the linguistic form of a translation for which a similarity analysis can be made. Such an analysis, he suggests, will make reference to the textual relations between the translation and the source text, non-translated texts in the target language, other translations and learner texts. Since similarity is a multi-place predicate, the translation profile also needs to refer to the socio-cultural context including the skopoi of the texts. As such, the translation profile only consists of descriptive features yielded by the similarity analysis and is therefore an appropriate instrument for quality assessment. If certain features in the translation profile can be generalized and if they show relations between broader systems and various fields, they will also contain some explanatory power.

According to Halverson, explanatory power can be provided by cognitive linguistics, which she applies to translation shifts, as they have been prominent in TS since the work by Vinay/Darbelnet (1958) and Catford (1965). In capturing the insights from previous work, she suggests an approach where translation shifts are seen as construal operations. She links different shifts to different construal operations which have explanatory power with regard to the former. Her examples are taken from the Oslo Multilingual Corpus.

While Chesterman stresses the asymmetry in Translation Studies with respect to a general feature in research (difference versus similarity), Nord observes that not much attention has yet been given so far to the phatic function of communication, which may be considered the most important of all possible communicative functions. She suggests a methodology for comparing phatic conventions across cultures, taking metacommunication as a case in point. She defines meta-communication as the sum total of verbal and nonverbal means used by a writer or speaker to comment on the conditions and factors of the communicative occurrence in progress. The three possible objects of meta-communicative utterances identified are: the situation, the participants and the text itself. In her exploratory study of a multilingual corpus of university manuals and handbooks, Nord compares some of the conventions of metacommunication. The results are considered as indicators of the culture-specificity of metacommunicative behaviour. They show that there is still much to be done in this field.

The volume also contains three empirical studies with a predominantly lexical orientation: Baker on idioms, Laviosa on anglicisms, and Marco Borillo and Guzman 
on body language words. A fourth paper by Vandepitte deals with predicates collocating with non-human agents, thus combining lexical aspects with syntactic ones. Baker sketches the state of the art of comparable corpus research that aims at finding the differences between translated and non-translated texts, i.e. the peculiarities of socalled translationese. Although definitions and boundaries between them are elusive, Baker states that explicitation, simplification, normalisation and standardisation are the most important broad features that have been investigated. Drawing upon the Translational English Corpus and the British National Corpus, she examines idiomatic phrases, a phenomenon that cannot easily be mapped onto these broad figures but seems particularly interesting to study from the viewpoint of normalisation. After discussing six features of idioms which she considers to be important for translation (fixedness, potential problems as cultural specificity, high degree of opacity together with an informal flavour, grammatical irregularity, low frequency and avoiding the literal use of the idiom), she investigates the use of the idioms 'off the hook' and 'out of order' in translations. Her pilot study reveals a clear preference for literal meanings of idiomatic expressions in translated English, which is certainly worth examining more closely.

Relying on a comparable corpus, too, Laviosa aims for two goals: to present a corpus-based methodology within a larger research project for studying anglicisms in cross- and inter-linguistic business communication and to report the findings from an initial application of the proposed methodology on the lemma of 'business'. She tries to assess the extent to which anglicisms are comparable complete units of meaning, whose analysis is intended to shed light on the sense relations between anglicisms and domestic competitors. An examination of the use of 'business' reveals that it has a range of meanings spread over several non-English equivalents, which are all (except for one) used more frequently, and that instead of replacing or adding meanings, it rather fulfils the role of differentiator, as it wedges itself into the semantic field in the receptor language. In her conclusions, Laviosa suggests ways in which the methodology proposed can be of interest to descriptive linguistics, LSP learning, translation training, lexicography and terminology.

The other two lexical studies present results from parallel corpus analyses. Marco and Guzman examine five simple verbs that denote bodily expression which frequently occur in English fiction (frown, gasp, shrug, sniff and stare) and their Catalan translations. The analysis is based on COVALT (Valencian Corpus of Translated Literature) and shows that Catalan translators mainly use the standard equivalents provided by the bilingual dictionary. However, evidence is also found of other, diverging tendencies such as explicitation (frown) and simplification (stare), findings which bear witness to translators' versatility and creativity.

Investigating the distribution of collocations of non-human agents and their predicates, Vandepitte tests the hypothesis that one of the three meaning-related Suniversals (implicitation, explicitation or change) will occur in those places where source and target languages have lexical items with similar semantic/pragmatic features but different collocational properties, as in English and Dutch. A meaning description model that starts from Portner's formal semantics and is enriched by a pragmatic component yields results - S-universals occur in almost two thirds of the examples which reveal some explanatory power: the occurrence of the S-universals can be 
explained by the non-human agents in the English original. While a small minority of changes can be related to pragmatic factors, most of them are found in the semantic component of predication. The high frequency of implicitations in this pilot study is not a typical result and needs further research.

Finally, there are five papers with a grammatical orientation: Lehtinen focuses on sentence structure, Espunya on connectives and Goethals on demonstratives. Buyse's paper on clitics marks the transition to the morphological domain, to which Chamonikolasová and Rambousek's paper on diminutives also contributes. Within the framework of cognitive grammar, Lehtinen examines how the pragmatic notion of subjectivity, i.e. invoking the speaker's or narrator's viewpoint in many different contexts, is construed in translations from English into Finnish and vice versa. She describes constructions typically used in both languages to express subjectivity (English static transitive, Finnish locative adverbial) and goes into the different characteristics of the subject and subject role in English and Finnish and its consequences in translation. The differences found between the source text and the translation are traced back to the differences between the functional categories of subject and word-order as well as to the differences in the use of the transitive prototype. In terms of imagery, Lehtinen states that the constructions used reflect basically different cognitive principles that govern the ways in which English and Finnish speakers structure and conceptualize events and situations.

Looking at interclausal discourse relationships, Espunya takes a textual approach and attempts to establish whether the pragmatic-cognitive principle of informativeness, which is claimed to influence linguistic explicitness in monolingual discourse production, also plays a role in translational explicitation. She focuses on English connectives in $\mathrm{V}$-ing free adjuncts, which show a correlation between informativeness and explicitness: if the relationship between the propositional contents of an English matrix clause and its free adjunct is very informative, the connection is expressed explicitly. Her own corpus of English-Catalan translation pairs, in which the Catalan translations are categorized as explicitations or non-explicitations, confirms this correlation, a finding that supports further investigation into the scale of informativeness.

Goethals looks at demonstrative determiners and pronouns in Spanish and Dutch source and target texts. Three types of asymmetry are discussed: demonstratives versus non-demonstrative definite determiners, pronouns versus full noun phrases, distal versus proximal demonstratives. He finds that Dutch demonstratives seem to be more grammaticalized than their Spanish counterparts, a hypothesis that is relevant for contrastive linguistics. The corpus also gives more evidence for the well-known explicitation hypothesis in Translation Studies: it reveals more full noun phrases in the translations than the source texts. Finally, the sample yields very different results with regard to the asymmetry between distal and proximal forms, a result which can only be explained by text linguistics or stylistics, i.e. the individual characteristics of the texts or the translator's individual preferences.

Buyse presents the results of a quantitative analysis of prosodic and pragmatic features of the Spanish translations of French clitic pronouns in representative parallel and comparable corpora. He argues that a universal translation mechanism enables the native translator to search for target text structures that express similar prosodic and 
pragmatic features. In addition, the clitic pronouns can be placed along a continuum that characterizes their equivalent translation capability. His findings can be used to improve the translation competence of (non-native) translators and translation students.

Chamonikolasová and Rambousek compare the frequencies of diminutives in English and Czech source texts and their translations. The analysis confirms a very high frequency of the use of diminutives in Czech in comparison with English. The source texts do not seem to affect the target texts: in terms of diminutive frequencies, translations into Czech do not differ significantly from non-translated Czech texts, and translations into English do not differ from non-translated English texts. Despite fluctuations related to the individual translator style and to the source text genre and style, the translators examined respect the target language conventions rather than 'copy' the source text structures.

To conclude, the volume presents results from descriptive linguistic investigations into translations, covering a wide variety of West-European languages: Catalan, Czech, Dutch, English, Finnish, French, German, Italian, Norwegian and Spanish. Sometimes, the results are based on large corpora and they allow researchers to generalize; in other cases, corpora need to be enlarged to confirm preliminary findings. We think the volume gives convincing evidence of the development of TS into a mature, empirical (inter)discipline, profiting from the technology-inspired evolutions in the field and from new orientations in linguistics towards a cognitively-inspired and usage-based theory of language.

\section{References}

Baker, M. 1993. "Corpus Linguistics and Translation Studies: Implications and applications”. In M. Baker, G. Francis and E. Tognini-Bonelli (eds), Text and Technology. In Honour of John Sinclair. Amsterdam and Philadelphia: J. Benjamins, 233-250

Baker, M. 1995. "Corpora in Translation Studies: an overview and some suggestions for future research". Target, 7(2): 223-243

Baker, M. 2004. "Linguistic models and methods in the study of translation". In H. Kittel, A.P. Frank, N. Greiner, T. Hermans, W. Koller, J. Lambert, F. Paul (eds.), Übersetzung Translation - Traduction. Ein internationales Handbuch zur Übersetzungsforschung. Berlin and New York: W. De Gruyter, 285-294.

Catford, J.C. 1965. A Linguistic Theory of Translation. An Essay in Applied Linguistics. London: Oxford University Press

Chesterman, A. 2004. "Beyond the particular". In A. Mauranen and P. Kujamäki (eds.), 33-49.

House, J. 1997. Translation Quality Assessment. A Model Revisited. Tübingen: Gunter Narr.

Malmkjær, K. 2005. "Translation and linguistics". Perspectives 13(1): 5-20.

Malmkjær, K. 2006. "Translation competence, linguistics and the aesthetic attitude". Paper presented at the International Conference on the Study of Language and Translation, Ghent University College, January 12-14.2006.

Mauranen, A. and Kujamäki, P. (eds.) 2004. Translation Universals. Do they Exist? Amsterdam and Philadelphia: J. Benjamins.

Nida, E.A. 1945. "Linguistics and ethnology in translation problems". Word 1, 194-208.

Snell-Hornby, M. 1988, Translation Studies: An Integrated Approach. Amsterdam and Philadelphia: J. Benjamins

Snell-Hornby, M. 2006. The Turns of Translation Studies. Amsterdam and Philadelphia: J. Benjamins 
Toury, G. 1995. Descriptive Translation Studies and Beyond. Amsterdam and Philadelphia: John Benjamins

Tymoczko, M. 2002. "Connecting the two infinite orders. Research methods in Translation Studies". In T. Hermans (ed.), Crosscultural Transgressions. Manchester: St. Jerome Publishing, 9-25.

Van Vaerenbergh, L. 2002 "Linguistics and Translation Studies. Translation Studies and Linguistics. Eine Einführung". In L. Van Vaerenbergh (ed.), Linguistics and Translation Studies. Translation Studies and Linguistics. Linguistica Antverpiensia, New Series 1, 1326.

Vinay, J.-P. and Darbelnet, J. 1958. Stilistique comparée du français et de l'anglais. Méthode de traduction. Paris: Didier (translated and edited by JcC. Sager and M.-J. Hamel (1995) as Comparative Stylistics of French and English. Amsterdam and Philadelphia: John Benjamins.

Wing-Kwong Leung, M. 2006. "The ideological turn in Translation Studies". In J.F. Duarte, A. Assis Rosa, T. Seruya (eds.), Translation Studies at the Interface of Disciplines. Amsterdam and Philadelphia: J. Benjamins, 129-144.

Wolf, M. (ed.) 2006. Übersetzen - Translating - Traduire. Towards a "Social Turn"? Münster etc.: LIT Verlag.

\section{Acknowledgements}

The twelve articles in this volume constitute a selection from the papers that were given at the three-day conference, which took place at University College Ghent, on January 12 to 14, 2006. The conference was organized under the auspices of the Belgian Linguistic Society. The organizers would like to thank the two Belgian Science Foundations, the Fonds voor Wetenschappelijk Onderzoek (Flanders), and the Fonds de Recherche Scientifique (French-sepaking Community), as well as the organization for translators and interpreters CIUTI (Conférence Internationale Permanente d'Instituts Universitaires de Traducteurs et Interprètes) for their financial support.

The organizers would like to thank the colleagues who helped us in the reviewing process for this volume: Johan Van der Auwera, Timothy Colleman, Sylviane Granger, José Lambert, Reine Meylaerts, Aline Remael and Leona Van Vaerenbergh.

We are also very thankful to the colleagues and students of the Ghent School of Translation Studies, for their helpful support with the organization. Specific mention goes to André Brisau, for his help with the linguistic revision, and Erik Tack, for his assistance in the lay-out work.

We trust that the present volume provides a reliable impression of the possibilities and gains to be gotten from the interface between Linguistics and Translation Studies. It offers, we hope, a representative sample of the kind of research that blossoms at the intersection of the two disciplines, and we hope it may be helpful to better put TS on the map of the academia in the Belgian and the European context. 